\title{
Diallel Analysis of Floral Longevity in Impatiens walleriana
}

\author{
Nicholas P. Howard and Dennis Stimart \\ Department of Horticulture, University of Wisconsin, Madison, WI 53706 \\ Natalia de Leon \\ Department of Agronomy, University of Wisconsin, Madison, WI 53706 \\ Michael J. Havey \\ USDA-ARS, Department of Horticulture, University of Wisconsin, Madison, WI 53706 \\ William Martin ${ }^{1}$ \\ Pan American Seed Company, 1S861 Green Road, Elburn, IL 60119
}

\begin{abstract}
AdDitional INDEX wORDs. general combining ability, specific combining ability
ABSTRACT. Impatiens (Impatiens walleriana) are currently among the most valuable and widely cultivated floriculture crops in the world. Attractive floral display is a primary goal for breeders of impatiens. Although breeders have selected for this trait, little consideration has been given to floral longevity as a means to increase the floral display of bedding crops. In this study, 259 commercial inbred lines of impatiens were grown in a greenhouse and evaluated for floral longevity as defined by the time between when a flower was completely open to when all of the petals abscised from the pedicle. Mean floral longevity of inbreds ranged from $3.3 \pm 0.4$ to $15.8 \pm 2.5$ days. Twelve inbreds (six with long floral longevity and six with short floral longevity) were chosen and crossed in a half diallel to create 66 hybrids that were analyzed for floral longevity in three greenhouse environments. Mean floral longevity of hybrids across greenhouse environments ranged from $2.8 \pm 0.4$ to $14.1 \pm \mathbf{2 . 8}$ days. Significant general (GCA) and specific (SCA) combining abilities for floral longevity were detected. GCA mean squares were 37 times larger than SCA mean squares, revealing that additive genetic effects play a more important role in the inheritance of floral longevity in impatiens. This information, coupled with the significant amount of variation for floral longevity among inbreds, indicates that there is good potential for breeding for floral longevity in impatiens to improve the floral display of hybrids.
\end{abstract}

Impatiens currently are among the most valuable and widely cultivated floriculture crops in the world (Uchneat, 2006). Its popularity is attributed to its wide array of available colors, preference for growing in shade, and ease of use as a container plant. Although the value of impatiens has been decreasing since 2002 [U.S. Deptartment of Agriculture (USDA), 2007], its estimated value in 2009 was $\$ 174$ million and the wholesale value was \$134 million (USDA, 2009).

Enhanced floral longevity has the potential to greatly increase the appeal of any floriculture crop, including impatiens. Although an attractive floral display is a primary goal of breeding in many ornamental crops, research on floral longevity has focused primarily on postharvest longevity in cut flowers. Narrow-sense heritability estimates were found at 0.66 to 0.88 (Weber et al., 2005) and 0.79 to 0.81 (Martin, 2002) in Antirrhinum majus, 0.51 to 0.59 in Dianthus caryophyllus (Burchi et al., 1999), 0.80 in Rosa $\times$ hybrida (De et al., 1999), 0.74 in Lilium (Van der Meulen-Muisers et al., 1999), 0.28 in Gerbera $\times$ hybrida (Wernett et al., 1996), and 0.00 to 0.38 in Gerbera jamesonii (Harding et al., 1981). Significant levels of

Received for publication 19 Sept. 2011. Accepted for publication 4 Nov. 2011. We gratefully acknowledge the financial support the commercial flower growers of Wisconsin distinguished graduate fellowship to N.P. Howard. Names are necessary to report factually on available data; however, the U.S. Department of Agriculture (USDA) neither guarantees nor warrants the standard of the product, and the use of the name by USDA implies no approval of the product to the exclusion of others that may also be suitable.

${ }^{1}$ Corresponding author. E-mail: BMartin@ballhort.com. general $(P<0.001)$ and specific combining ability $(P<0.046)$ were also reported for Lilium (Van der Meulen-Muisers et al., 1999). Significant additive gene effects were detected for detached floral longevity in the bedding crop Petunia $\times$ hybrida (Krahl and Randle, 1999). Carlson (2008) investigated the genetics of intact floral longevity in impatiens and found nonsignificant variation for floral longevity for data collected in the spring but significant variation for floral longevity for data collected in the summer and estimated narrow-sense heritability at 0.46 . However, Carlson (2008) measured days to "loss of ornamental value in terms of petal turgidity and color intensity," which refers more to a measurement of days to color fade instead of a direct measurement of floral longevity.

In this study, 259 commercial inbred lines of impatiens were evaluated for floral longevity. A set of 12 inbreds was selected for diallel crossing to estimate GCA and SCA for floral longevity. These estimates can be used to determine how much genetic variation for floral longevity in impatiens is the result of additive or dominant gene action, which can be used to design breeding approaches to produce impatiens with better floral display.

\section{Materials and Methods}

Plant material. Two hundred fifty-nine proprietary inbred lines of $I$. walleriana were provided by PanAmerican Seed, West Chicago, IL (listed in Howard, 2011). Each inbred had been self-pollinated for a minimum of five generations and many were inbred beyond $\mathrm{S}_{12}$ through single seed descent. 
Definition of Floral LONGEVITY. Floral longevity was defined as the time between when a flower was completely open to when all of the petals abscised from the pedicle. The first three opened flowers on each plant were tagged and dated. The second date was noted when all petals were completely abscised. Occasionally, one or more of the first three flowers were not tagged because flowers grew under leaves or were too close to already tagged flowers to be tagged without causing damage to adjacent flowers. These flowers were ignored and later opening flowers were tagged.

Evaluation OF INBREDS. Inbred lines were sown on 1 Sept. 2009 in DC Smith Greenhouse at the University of WisconsinMadison into 288-well plug trays with Fafard \#2 media (Conrad Fafard, Agawam, MA) and grown under a 40\% shadecloth canopy with no supplemental light. After 2 weeks, plants were fertilized once per week with $100 \mathrm{mg} \cdot \mathrm{L}^{-1}$ nitrogen $(\mathrm{N})$ of $21 \mathrm{~N}$ 2.2P-16.6K fertilizer (Peters Excel; Scott's, Marysville, $\mathrm{OH}$ ) until transplanting. The impatiens were transplanted on 2 Oct. into square $10 \times 10 \times 8.9-\mathrm{cm}$ pots in a greenhouse at the West Madison Agricultural Research Station, Verona, WI. Nine plants from each inbred were transplanted and three were randomly assigned to each of three replications. Pots were spaced $15 \mathrm{~cm}$ apart. Each replication covered 1.5 benches in the greenhouse. There were only two replications for 30 inbreds as a result of poor germination or weak seedlings. Plants were fertilized once per week with $300 \mathrm{mg} \cdot \mathrm{L}^{-1} \mathrm{~N}$ of $20 \mathrm{~N}-3.9 \mathrm{P}-$ 16.6K fertilizer (Technigro; Sun Gro Horticulture, Bellevue, WA). Data were taken on floral longevity between 26 Oct. and early Dec. 2009.

STATISTICAL ANALYSIS OF FLORAL LONGEVITY IN INBREDS. Floral longevity was averaged across three flowers from each plant. The mean, SD, and minimum and maximum values were calculated for floral longevity for each inbred line. Normality of the data was assessed using the Shapiro-Wilk test. A one-way analysis of variance (ANOVA) was done using a general linear model in which inbred lines were considered a fixed effect and replications were considered random using SAS (Version 9.13; SAS Institute, Cary, NC). Inbred mean separation was completed using Fisher's least significant difference test $(P<0.05)$.

Diallel evaluation of HYBRids. Six inbreds from both of the longest and shortest floral longevity groups were chosen for the diallel analysis. A method four (half diallel excluding parents) diallel design was used to estimate GCA and SCA of floral longevity (Griffing, 1956). This design assumed no maternal effects and seed from reciprocal crosses was bulked to produce enough seed for analysis of hybrids. Sixty-six $F_{1}$ hybrids were generated during the Winter and Spring 2010 by hand pollination in the greenhouse at the West Madison Agricultural Research Station. Cleaned seed from each fruit was collected and stored at $2{ }^{\circ} \mathrm{C}$ and $80 \%$ humidity. Hybrids were evaluated in three greenhouse environments at the West Madison Agriculture Research Station. Seeds for the first greenhouse environment were sown in 21 July 2010, the resulting plants were transplanted on 25 Aug., and data were collected in September and October. Seeds for the second greenhouse environment were sown 6 Oct. 2010, plants transplanted on 9 Nov., and data collected between Dec. 2010 and Jan. 2011. Seeds for the third greenhouse environment were sown in 11 Jan. 2011, plants transplanted on 15 Feb., and data collected between Mar. and Apr. 2011. Hybrids were evaluated in the same manner as previously described for inbreds. Nine plants of each hybrid were transplanted and three were assigned randomly to each of three replications and grown as previously described.

Statistical ANALYSIS OF HYBRIDS. Floral longevity was averaged for three flowers from each plant. Normality, means, SDS, minimum, and maximum values were calculated as previously described for inbreds. A mixed ANOVA model was performed using SAS in which hybrids were considered a fixed effect and environment, replication, and the interaction between hybrid and environment were assumed to be random. Because a significant hybrid-by-environment interaction was observed, Spearman's rank correlations among the three greenhouse environments were calculated in $\mathrm{R}$ (Version 2.11.1; R Project for Statistical Computing, Vienna, Austria) and used to determine if the data could be pooled. Because parental inbreds were selected based on differing floral longevities, an estimate of repeatability (Lorenz and Coors, 2008) was calculated instead of broad-sense heritability as follows: $R=\sigma_{\mathrm{g}}^{2} /\left[\sigma_{\mathrm{g}}^{2}+\left(\sigma_{\mathrm{ge}}^{2} / \mathrm{e}\right)+\left(\sigma^{2}{ }_{\text {err }} / \mathrm{r} \times \mathrm{e}\right)\right]$, where $\sigma^{2}$ denotes hybrid variance, $\sigma_{\text {ge }}^{2}$ denotes the variance attributed to the interaction among hybrids and environments, $\sigma^{2}$ err denotes environmental variance, and $r$ and e are replications and greenhouse environments, respectively. The average floral longevity data were averaged across replications within each greenhouse environment for the diallel analysis. Griffing's (1956) method four (half diallel excluding parents), Model 1 (fixed genotypes) was used in SAS to determine the GCA and SCA as described in Howard (2011).

\section{Results}

INBREDS. Mean floral longevity for inbreds was $9.2 \pm 2.7 \mathrm{~d}$ and the minimum and maximum average floral longevities were $3.3 \pm 0.4$ and $15.8 \pm 2.5 \mathrm{~d}$, respectively. The Shapiro-Wilk test indicated a non-normal distribution of floral longevity data $(P=0.002)$. However, visual inspection of the $\mathrm{Q}-\mathrm{Q}$ plot (reported in Howard, 2011) did not show obvious problems with the data. Several transformations (including logarithmic, square root, and Box-Cox) were completed but none normalized the data. Therefore, the original data were analyzed. The one-way ANOVA revealed significant differences among inbred lines for floral longevity $(P<0.001)$, from which 12 inbreds were selected for diallel analysis (Table 1).

Table 1. Average floral longevity of Impatiens walleriana inbreds used in the diallel design.

\begin{tabular}{lc}
\hline Inbred line no. & Avg floral longevity $(\mathrm{d})^{\mathrm{z}}$ \\
\hline 206 & $14.1 \mathrm{a}$ \\
126 & $14.0 \mathrm{a}$ \\
211 & $13.4 \mathrm{a}$ \\
104 & $13.3 \mathrm{a}$ \\
287 & $13.2 \mathrm{a}$ \\
48 & $12.8 \mathrm{a}$ \\
152 & $6.0 \mathrm{~b}$ \\
56 & $5.8 \mathrm{~b}$ \\
15 & $5.1 \mathrm{~b}$ \\
247 & $5.1 \mathrm{~b}$ \\
51 & $5.0 \mathrm{~b}$ \\
252 & $4.8 \mathrm{~b}$ \\
\hline
\end{tabular}

${ }^{\mathrm{z}}$ Different letters indicate significant separation by Fisher's least significant difference (3.1) at $P=0.05$. 
Hybrids. Mean floral longevity for hybrids across all three greenhouse environments was $7.8 \pm 2.1 \mathrm{~d}$ and the minimum and maximum average floral longevities were $2.8 \pm 0.4$ and $14.1 \pm$ $2.8 \mathrm{~d}$, respectively. The Shapiro-Wilk test showed that the combined data across all three greenhouse environments were not normally distributed $(P<0.001)$ and did not transform to normality using logarithmic, square root, and Box-Cox transformations. Further Shapiro-Wilk tests showed that the data from greenhouse Environment 1 departed significantly from normality $(P<0.001)$, whereas data from greenhouse Environments 2 and 3 were normally distributed (combined $P=$ 0.3646). Therefore, data from greenhouse Environments 2 and 3 were used for ANOVA and the diallel analyses. The mixed model ANOVA found significant effects for hybrids $(P<$ $0.0001)$, environment $(P=0.0004)$, and the interaction between hybrid and environment $(P<0.0001)$; replications were not significant $(P=0.2075)$. The Spearman's rank correlation coefficient, calculated as a result of a significant hybrid-byenvironment interaction, between greenhouse Environments 1 and 2 was 0.71 , between greenhouse Environments 2 and 3 was 0.79 , and between greenhouse Environments 1 and 3 was 0.69 . All of these values were significant at $P<0.05$. The repeatability estimate was 0.72 , indicating that a majority of the observed variation is genetic relative to environmental effects and their interactions.

The ANOVA for the diallel analysis revealed significant GCA, SCA, environments, environment-by-GCA, and environmentby-SCA interactions (Table 2). GCA values for long-florallongevity parents ranged from 0.10 to $1.57 \mathrm{~d}$ and GCA values for short-floral-longevity parents ranged from -1.62 to $0.70 \mathrm{~d}$ (Table 3). One parent (247) in the short-floral-longevity group had a positive GCA value (Table 3). SCA values ranged from -1.18 to $1.79 \mathrm{~d}$ across hybrids (Table 4).

\section{Discussion}

The diallel analysis shows highly significant GCA and SCA for floral longevity in impatiens (Table 2). These results contrast with previous work with related impatiens germplasm by Carlson (2008), which found a non-significant narrow-sense heritability estimate $(0.23)$ for spring data and a slightly significant narrow-sense heritability estimate $(0.46)$ in the summer. As mentioned previously, the definition of floral longevity used by Carlson (2008) measured color fade instead of floral abscission. Results from a study on Petunia $\times$ hybrida detected significant GCA but nonsignificant SCA by measuring corolla wilting on detached flowers, a trait correlated with the longevity of intact flowers (Krahl and Randle, 1999).

Significant GCA and SCA indicate additive and non-additive genetic effects are important in the inheritance of floral longevity, respectively (Sprague and Tatum, 1942). Analysis of the diallel showed that the GCA mean squares were 37 times larger than SCA (Table 3), indicating that additive genetic effects Station in Verona, WI. are more important in the inheritance of floral longevity in impatiens. Inbred parents with short or long floral longevity tended to produce hybrids with similar floral longevities. All six inbred lines with long floral longevity showed positive GCA,

Table 2. Analysis of variance for floral longevity in days of hybrid Impatiens walleriana from a half diallel excluding parents grown in greenhouse Environments 2 and $3^{z}$ at the West Madison Agricultural Research Station in Verona, WI.

\begin{tabular}{lrrr}
\hline Source $^{\mathrm{y}}$ & Df & Mean square & \multicolumn{1}{c}{$P$} \\
\hline Environment & 1 & 12.69 & $<0.0004$ \\
Replication & 2 & 1.57 & 0.2102 \\
GCA & 11 & 83.60 & $<0.0001$ \\
SCA & 54 & 2.28 & $<0.0001$ \\
Environment $\times$ GCA & 11 & 5.15 & $<0.0001$ \\
Environment $\times$ SCA & 54 & 2.57 & $<0.0001$ \\
Error & 262 & 1.00 &
\end{tabular}

${ }^{\mathrm{z} E n v i r o n m e n t} 2$ data were collected between Dec. 2010 and Jan. 2011; Environment 3 data were collected between Mar. and Apr. 2011.

${ }^{\mathrm{y}} \mathrm{GCA}=$ general combining ability; SCA = specific combining ability.

Table 3. General combining ability (GCA) in Impatiens walleriana for floral longevity in days in a half diallel across greenhouse Environments 2 and $3^{z}$ at the West Madison Agricultural Research Station in Verona, WI.

\begin{tabular}{lr}
\hline Inbred parent no. ${ }^{\mathrm{y}}$ & $\mathrm{GCA}$ \\
\hline 206 & 0.89 \\
126 & 1.57 \\
211 & 0.83 \\
104 & 0.10 \\
287 & 1.40 \\
48 & 0.68 \\
152 & -1.62 \\
56 & -1.36 \\
15 & -1.56 \\
247 & 0.70 \\
51 & -0.49 \\
252 & -1.14 \\
\hline
\end{tabular}

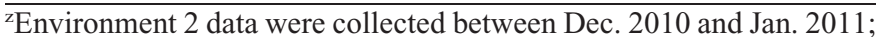
Environment 3 data were collected between Mar. and Apr. 2011. ${ }^{\mathrm{y}}$ Inbred parents are listed in Table 1.

Table 4. Specific combining ability (SCA) in Impatiens walleriana for floral longevity in days in half diallel across greenhouse Environments 2 and $3^{z}$ at the West Madison Agricultural Research

\begin{tabular}{llllrrrrrrrr}
\hline Parents $^{\mathrm{y}}$ & 126 & 211 & 104 & \multicolumn{1}{c}{287} & \multicolumn{1}{c}{48} & \multicolumn{1}{c}{152} & \multicolumn{1}{c}{56} & \multicolumn{1}{c}{15} & 247 & \multicolumn{1}{c}{51} & 252 \\
\hline 206 & -0.19 & 0.01 & 0.24 & -1.13 & 0.35 & -0.45 & -0.09 & 0.3 & 0.4 & 0.47 & 0.1 \\
126 & & 0.97 & -0.15 & -0.32 & -0.06 & 0.22 & -0.76 & 0.46 & -0.32 & -0.26 & 0.43 \\
211 & & & -0.06 & -0.05 & -0.74 & -0.64 & 0.31 & -0.44 & 0.45 & 0.24 & -0.03 \\
104 & & & & 0.35 & 0.49 & 0.34 & 0.25 & -0.52 & 0.33 & -1.18 & -0.08 \\
287 & & & & & -1.03 & 1.17 & -0.59 & 0.39 & 1.79 & -0.58 & 0.02 \\
48 & & & & & & 0.54 & 0.17 & 0.58 & -0.23 & 0.18 & -0.24 \\
152 & & & & & & & 0.07 & -0.89 & -0.28 & 0.93 & -0.99 \\
56 & & & & & & & & 0.22 & -0.71 & 0.47 & 0.67 \\
15 & & & & & & & & & -0.53 & 0.36 & 0.08 \\
247 & & & & & & & & & & -0.78 & -0.1 \\
51 & & & & & & & & & & & 0.16
\end{tabular}

$\overline{{ }^{\mathrm{z}} \text { Environment } 2 \text { data were collected between Dec. } 2010 \text { and Jan. 2011; Environment } 3 \text { data were }}$ collected between Mar. and Apr. 2011.

${ }^{\mathrm{y}}$ Floral longevity of inbred parents is listed in Table 1. 
although inbred line 104 had a GCA of only +0.10 (Table 3). Five of the six inbred lines that possessed short floral longevity had negative GCA. Although inbred 247 had a positive GCA of 0.70 , this value reflects particularly high positive SCA with long-floral-longevity inbred 287 (Table 4).

Although a significant hybrid-by-environment interaction was detected, Spearman's rank correlations indicated that there were no significant rank changes for floral longevity between hybrids across the three greenhouse environments. Therefore, the hybrid-by-environment interaction must be the result of relative mean differences between the greenhouse environments producing a change in magnitude, but not in direction, of the response across environments. The repeatability estimate also supported lower environmental effects and interactions relative to genetic effects. Overall results show that there is a significant genetic component for floral longevity in the inbreds used in this study, mostly as a result of additive gene effects (Tables 4). This information, coupled with the significant amount of variation for floral longevity among inbred populations, indicates that there is potential for breeding for this trait in impatiens to improve the floral display of hybrids. However, selection for longer floral longevity must be balanced with other floral traits such as color fade to enhance the overall floriferousness of hybrid impatiens.

\section{Literature Cited}

Burchi, G., C. Bianchini, A. Mercuri, G. Foglia, D. Rosellini, and T. Schiva. 1999. Analysis of post-harvest flower life in a cross between carnation cultivars with different ethylene responses. J. Genet. Breed. 53:301-306.

Carlson, C. 2008. Genetic analysis of commercially important phenotypic traits in inbred lines and their F1 hybrids of Impatiens walleriana Hook F. MS thesis, Univ. of Wisconsin, Madison, WI.
De, L.C., S.D. Wahi, and S.K. Bhattacharjee. 1999. A post-harvest study of genetic divergence in cut roses. Indian J. Genet. Plant Breed. 59:351-356.

Griffing, B. 1956. Concept of general and specific combining ability in relation to diallel crossing systems. Aust. J. Biol. Sci. 9:463493.

Harding, J., T.G. Byrne, and R. Nelson. 1981. Heritability of cutflower vase longevity in Gerbera. Euphytica 30(2):653-657.

Howard, N. 2011. Diallel analysis of floral longevity in Impatiens walleriana. MS thesis, Univ. of Wisconsin, Madison, WI.

Krahl, K.H. and W.M. Randle. 1999. Genetics of floral longevity in Petunia. HortScience 34:339-340.

Lorenz, A. and J.G. Coors. 2008. What can be learned from silage breeding programs? Appl. Biochem. Biotechnol. 148:261-270.

Martin, W.J. 2002. Postharvest biology and genetics of Antirrhinum majus L., snapdragon. PhD diss. 3072823, Univ. Wisconsin, Madison, WI.

Sprague, G.F. and L.A. Tatum. 1942. General vs. specific combining ability in single crosses of corn. J. Amer. Soc. Agron. 34:923-932.

Uchneat, M.S. 2006. Impatiens, p. 277-299. In: Anderson, N.O. (ed.). Flower breeding and genetics: Issues, challenges and opportunities for the 21 st century. Springer, Dordrecht, The Netherlands.

U.S. Department of Agriculture. 2007. Floriculture and nursery crops yearbook. U.S. Dept. Agr., Washington, DC.

U.S. Department of Agriculture. 2009. USDA census of horticultural specialties. U.S. Dept. Agr., Washington, DC.

Van der Meulen-Muisers, J.J.M., J.C. van Oeveren, J. Jansen, and J.M. van Tuyl. 1999. Genetic analysis of postharvest flower longevity in Asiatic hybrid lilies. Euphytica 107:149-157.

Weber, J.A., W.J. Martin, and D.P. Stimart. 2005. Genetics of postharvest longevity and quality traits in late generation crosses of Antirrhinum majus L. J. Amer. Soc. Hort. Sci. 130:694-699.

Wernett, H.C., G.J. Wilfret, T.J. Sheehan, F.G. Martin, T.L. White, G.L. Powell, and C. Wilcoz. 1996. Postharvest longevity of cut-flower Gerbera. II. Heritability of vase life. J. Amer. Soc. Hort. Sci. 121:222-224. 